\title{
RECURRENCE AFTER RADICAL HYSTERECTOMY IN EARLY CERVICAL CANCER PATIENTS
}

M. M. A. Sousa*, G. F. Cintra, R. Dos Reis, M. A. Vieira, M. H. Santos, C. E. M. C. Andrade Barretos Cancer Hospital - Brazil

\section{Background \& Objectives}

The objective of this study is to estimate the recurrence rate in women with early-stage cervical cancer (stages IA1 with LVSI, IA2 and IB1) underwent radical hysterectomy and pelvic lymphadenectomy and evaluate the recurrence by the surgical approach (laparoscopy vs laparotomy)

\section{Methods}

A retrospective study was conducted in patients who underwent radical hysterectomy and pelvic lymphadenectomy for early stage cervical cancer at Barretos Cancer Hospital from January 2009 to March 2017. Were evaluate the recurrence rate, surgical approach and the pathologic risk factors, as histological type, tumor grade, tumor size, LVSI, stromal invasion and lymph node status. The statistical analyses were performed using Chisquare and Fisher tests and logistic model to evaluated possible confounding factors.

\section{Outcomes}

An evaluation was conducted of 139 patients. The rate of tumor recurrence was $10.8 \%$ (15). The characteristics of the tumor in patients with recurrence are described in table 1 . The surgical approach was laparoscopy (conventional or robotic) in $107(77 \%)$ patients and laparotomy in $32(23 \%)$ patients. About the patients with recurrence, 13 patients underwent a laparoscopy approach, and only 2 patients underwent a laparotomy approach.

HOSPITAL DE CÂNCER DE BARRETOS Fundação Pio XII (ii)
Table 1 - The histopathological and surgical characteristics of the tumor in patients with recurrence

\begin{tabular}{cccc}
\hline & & $\mathrm{n}=15$ & $\%$ \\
\hline $\begin{array}{c}\text { Histological } \\
\text { Type }\end{array}$ & Squamous cell & 7 & $46.7 \%$ \\
\hline $\begin{array}{c}\text { Clinical Stage } \\
\text { (before the } \\
\text { surgery) }\end{array}$ & 1A1 com LVSI & 1 & $6 \%$ \\
\hline $\begin{array}{c}\text { Surgical } \\
\text { approach }\end{array}$ & laparoscopy & 14 & $94 \%$ \\
\hline $\begin{array}{c}\text { Residual } \\
\text { disease on } \\
\text { final }\end{array}$ & laparotomy & 2 & $13.3 \%$ \\
pathology & present & 15 & $100 \%$ \\
\hline
\end{tabular}

Table 2 - Distribution of risk factors to recurrence in patients with early stage cervical cancer at the final histology

\begin{tabular}{cccc}
\hline & & $\mathrm{n}=15$ & $\%$ \\
\hline Tumor size $(\mathrm{cm})$ & $\leq 2 \mathrm{~cm}$ & 6 & $40 \%$ \\
& $>2 \mathrm{~cm}$ & 9 & $60 \%$ \\
\hline LVSI & present & 9 & $60 \%$ \\
& absent & 6 & $40 \%$ \\
\hline Margins & free & 15 & $100 \%$ \\
& positive & 0 & $0 \%$ \\
\hline Status lymph nodes & free & 15 & $100 \%$ \\
& positive & 0 & $0 \%$ \\
\hline Post operative & yes & 5 & $33.3 \%$ \\
adjuvant treatment & no & 10 & $66.7 \%$ \\
\hline Parametrial & yes & 1 & $6 \%$ \\
involvement & & 14 & $94 \%$ \\
\hline
\end{tabular}

\section{Conclusion}

In conclusion, it can be suggested that patients underwent radical hysterectomy with pelvic lymphadenectomy by laparoscopic approach have more risk of recurrence that laparotomy approach, according to the results of LAAC trial. This study has some limitations like to be a retrospective study. However, it is a study with a satisfactory number of patients included, performed in a single center, where the conduct in the cases of early stage cervical cancer and the surgical technique of radical hysterectomy are standardized and do not suffer major changes among surgeons. 